\title{
MIDDLE EAR DISORDERS AMONG CLEFT LIP AND PALATE IN CHILDREN: A CONJOINT EXPOSITION
}

\author{
Saba Islam, Nazia Mumtaz*, Ghulam Saqulain** \\ Nishtar Hospital, Multan Pakistan, *Shifa Tameer-e-Millat University, Islamabad Pakistan, ${ }^{* *}$ Capital Hospital, Islamabad Pakistan
}

\begin{abstract}
Objective: To analyze the frequency of middle ear disorders among the cleft lip and palate and association with hearing Loss Study Design: Cross Sectional analytical study.

Place and Duration of Study: Audiology Department of Cleft Hospital, Gujrat and ENT department of National Institute of Rehabilitation Medicine, Islamabad, from Oct 2018 to Mar 2019.

Methodology: We recruited a sample of 100 cleft lip and palate children of both genders, aged 3 month to 12 years, using nonprobability sampling. Screening was performed with otoscopy, tympanometry and hearing assessment.

Results: Out of sample population, $62 \%$ were males and $38 \%$ females with a mean age of $2.27 \pm 2.73$ years. The middle ear disorders were found to be $70 \%$. Among these otitis media with effusion was the most common 43 (61.43\%), followed by Acute otitis media $8(11.43 \%)$ and Eustachian tube dysfunction $6(8.57 \%)$. Tympanosclerosis and dry tympanic membrane perforation were the least common. Statistically significant association of hearing loss was found with the middle ear disorders $(p<0.001)$.

Conclusion: Middle ear disorders especially otitis media with effusion are common in cleft lip/ palate children.
\end{abstract}

Keywords: Cleft lip/palate, Developmental anomalies, Hearing loss, Middle ear disorders.

How to Cite This Article: Islam MS, Mumtaz N, Saqulain G. Middle Ear Disorders Among Cleft Lip and Palate in Children: A Conjoint Exposition Pak Armed Forces Med J 2021; 71 (Suppl-3): S457-461. Doi: https://doi.org/10.51253/pafmj.v1i1.3687

This is an Open Access article distributed under the terms of the Creative Commons Attribution License (https://creativecommons.org/licenses/by-nc/4.0/), which permits unrestricted use, distribution, and reproduction in any medium, provided the original work is properly cited.

\section{INTRODUCTION}

Lip and palatal clefts are developmental anomalies of the lip, palate, or both which result when components of the lip and/or the roof of the mouth fail to unite during fetal growth and have variable presentations. ${ }^{1}$ Clefts of lip and palate are conjoint variances with an estimated incidence of approximately 1 in 700 live births, more commonly witnessed in developing countries, with cleft lip and palate (CLP) being the commonest, followed by cleft palate (CP) and cleft lip (CL) in decreasing order of frequency. ${ }^{2}$ A local study reported a frequency of $57.53 \%$ with cleft lip with or without cleft palate, while $42.5 \%$ had cleft palate alone, ${ }^{3}$ and around half of clefts occur as part of a genetic syndrome. Clefts may be associated with Eustachian tube dysfunction resulting in Middle Ear Disorders (MED) may be seen in cleft patients mandating careful otologic and audiologic examination. ${ }^{4}$ Heidsieck et al. reported that the action/effect of tensor-velipalatini muscle responsible for opening and closing of Eustachian tube is altered in cleft children due to anatomical variations which result in MEDs. ${ }^{5}$

Otitis media with effusion is quite common in $\mathrm{CP}$ patients, ${ }^{6}$ and other MEDs may follow like chronic

Correspondence: Dr Ghulam Saqulain, HOD of Otolaryngology, Capital Hospital PGMI, CDA Islamabad-Pakistan suppurative otitis media (CSOM), acute otitis media (AOM), acute suppurative otitis media (ASOM), Eustachian tube dysfunction (ETD), Tympanic membrane (TM) perforation, and Tympanosclerosis (TS) may follow. Though young children with cleft palate often present with improved tubal function and hearing, however a considerable proportion of this group demonstrate secondary changes in the middle ear. ${ }^{7}$ Hence keeping in view the high incidence of MEDs in children with clefts Otological evaluation is essential, ${ }^{8}$ since long-run hearing impairment has been shown to negatively impact the language development of children. ${ }^{9}$

Because of the high likelihood of prevalence of ME pathologies and hearing impairments, children with $\mathrm{CP}$ are at inflated risk for communication disorders. ${ }^{6}$ Hence, it is of utmost importance to know the prevalence and risk factors of development of MEDs in cleft patients in our region to enhance early diagnosis and management of these patients. Therefore, the current study was conducted with objective to analyze the frequency of middle ear disorders among children with cleft lip and/or palate and association with demographic and clinical variables.

\section{METHODOLOGY}

This was a cross sectional analytical study was conducted at Audiology Department of Cleft Hospital, 
Gujrat and ENT department of National Institute of Rehabilitation Medicine, Islamabad, Pakistan following ethical approval from Institutional Research Board of Isra University vide Reg. No. 1702-M.Phil HS-002 dated 23rd October, 2018.

Using the following formula with a population proportion of $0.77 \% 10$, DEFF (estimated effective size) of 0.95 , using $5 \%$ absolute precision and $95 \%$ level of confidence a sample size of 96 was calculated.

$$
N=\frac{z_{\alpha / 2}^{2} * p *(1-p) * D E F F}{d^{2}}
$$

Inclusion Criteria: Non-syndromic cleft lip and palate cases of both genders, aged 3 month to 12 years were included.

Exclusion Criteria: Cases with upper respiratory tract infections within last week were excluded.

Non-probability consecutive sampling technique was used. Data collection was performed after obtaining consent of patients basic demographic sheet were filled followed by evaluation with otoscopy and then tympanometry to evaluate middle ear function (except in cases with acute otitis media or discharging ears) and finally hearing screening using brain stem evoked response audiometry (BERA) in children less than 5 years and Pure tone Audiometry for those above 5 years. This was followed by radiographs of the mastoids to see pneumatization and any pathology.

Pneumatic otoscopy and tympanometry are key investigations to diagnose MED's. Hence pneumatic otoscopy was done by specialist to exclude any obstruction in the canal and assess the status of the tympanic membrane (TM) and middle ear (perforation with and without discharge as in case of ASOM, CSOM; congested TM as in case of AOM; retracted, dull TM, fluid level and bubbles in middle ear as in case of OME; white patches as in case of tympanosclerosis). AOM was diagnosed on the basis three diagnostic criteria 11 including rapid onset symptoms of pain, fever and HL, TM inflammation and pus in the middle ear. When the fluid in the middle ear is sterile with no symptoms of inflammation it is considered OME, while purulent fluid coming out of middle ear with an acute history would suggest ASOM and one with a chronic course represented CSOM. Tympanometer model TSM 400 (France), was used to objectively assess the middle ear function including the mobility of the TM and conduction of sound through the middle ear and the type of tympanometry graph to diagnose MED's according to Liden-Jerger system 12 were recorded to diagnose different pathologies i.e. type " $\mathrm{A}$ " tympanogram (normal middle ear function), type "As" (shallow graph with low compliance at ambient pressure seen in otosclerosis), type "Ad" tympanogram (ossicular dislocation), type " $B$ " tympanogram (this is a dome shaped graph showing immobility due to fluid in ME and represents $\mathrm{OME}$ ), type " $\mathrm{C}$ " tympanogram (with negative middle ear pressure for Eustachian tube dysfunction). For this tympanometry was combined with Toynbee test and a shift of peak tympanometric pressure of $>10$ daPa represented normal and less pressure represented ETD. BERA Racia Alvar "Centor" was used for objective assessment of hearing status of less than 5 years old children who could not respond to sound, to test the auditory pathway from the ear to brain stem and assess the hearing threshold in these patients. PTA is the standard hearing test for population 5 years and older to assess the hearing threshold, degree, type and configuration of hearing and was performed at frequencies of $250 \mathrm{~Hz}$ to $8 \mathrm{KHz}$ and a hearing threshold of up to 20 decibels was considered normal, $20-40 \mathrm{~dB}$ as mild HL, 41-60 dB as moderate HL, 61-80 dB as severe $\mathrm{HL}$ and above $81 \mathrm{~dB}$ as profound loss. ${ }^{13}$ Pure tone audiometry was performed with audiometer with Model AD226 and made in Denmark, in a sound treated room.

Data collected was analyzed using Statistical Package for the social sciences (SPSS) version 23 with age presented by Mean \pm Standard Deviation and categorical variables presented by frequency and percentage. Pearson's chi-square test was used to find out the association and $p$-value of $\leq 0.05$ was considered significant.

\section{RESULTS}

Current study with a sample 100 included $62 \%$ males and $38 \%$ females and a mean age of $2.27 \pm 2.73$ years, with the age range of 3 month to 12 years and majority $87 \%$, in the age group of 3 month to 6 years. Majority $64 \%$ of the children had both cleft lip and palate, while cleft palate was second commonest $27 \%$. Sample included $49 \%$ cases of repaired and $51 \%$ cases of unrepaired clefts. Table-I showed statistically significant association of MED with age, cleft type and surgery. Majority of cleft cases of age group 3 month to 6 years developed MED and association was not significant with $p=0.029$. similarly MED's were associated with cleft type with 23 out of 27 cases of cleft palate and 46 out of 64 cases of cleft lip and palate being affected and the finding was statistically significant with $p<0.001$. Also MEDs were more common in non- 
operated cases (46 out of 51) compared to operated cases (24 out of 49) and association was significant with $p<0.001$, while no gender association was noted, while HL did not show any significant association with age, gender, cleft type and surgery $(p=0.400,0.639$, $0.068,0.483)$. Among these OME was most common 43 $(61.43 \%)$, followed by AOM $8(11.43 \%)$, ETD $6(8.57 \%)$, ASOM 5 (7.14\%) and CSOM 4 (5.73\%). Tympanosclerosis and dry TM perforation were the least common with $2(2.85 \%$ each). Table-II showed the frequency of $\mathrm{HL}$ among $\mathrm{CL} / \mathrm{P}$ children with ME disorders. Of the $70 \%$ cases with MED's, 34 (48.57\%) were suffering from HL, while 36 (51.43\% were having normal hearing; compared to no HL reported in cases in which MEDs were not present. This observation was statistically significant with $p$-value of $<0.001$. Of the patients with middle ear disorders, $48.58 \%$ had hearing loss mostly in mild to moderate range while $51.42 \%$ had normal hearing threshold. Most of the children had conductive hearing loss while a few with mixed hearing loss. their study that there was a high prevalence of abnormal middle ear status in cleft patients. ${ }^{14}$

In the present study, among the MEDs found in cleft lip and/or palate cases OME was the most prevalent $(43,61.43 \%)$, followed by AOM $(8,11.43 \%)$, ETD (6, 8.57\%), ASOM (5, 7.14\%) and CSOM (4, 5.73\%). Tympanosclerosis and Dry TM perforation were the least common with $(2,2.85 \%$ each). Similarly, a high prevalence of OME $(72.5 \%)$ was reported by Ahmed and Saqulain in a local study 6. Klaiarasi et al, in their study found that OME was the commonest abnormality detected in 94 ears $(48.9 \%)$, while cholesteatoma was seen in 6 cases $(3.1 \%)$, while in $0-5$ years age group $55.5 \%$ had OME and $44.5 \%$ of those above 10 years of age had chronic otitis media of squamous type. ${ }^{8}$ Narayanan et al, also reported significant higher prevalence of OME in cleft children. ${ }^{15}$ Lehtonen et al, also reported that $\mathrm{ME}$ infections were frequent with mucous secretions noted in $96.8 \%$ of $\mathrm{CL} / \mathrm{P}, 69.2 \%$ of $\mathrm{CP}$ and $13 \%$ of CL cases; while the prevalence of TM perforations was $35.9 \% .{ }^{16}$ In contrast, Kumari et al, in an Indian study reported the prevalence of OME as $16.6 \%$,

Table-I: Demographic and clinical characteristics (n=100)

\begin{tabular}{|c|c|c|c|c|c|c|c|}
\hline \multicolumn{2}{|c|}{ Demographic \& Clinical Characteristics } & \multicolumn{3}{|c|}{ Middle Ear, Disorder Type } & \multicolumn{3}{|c|}{ Hearing Loss } \\
\hline Variable & Characteristic & Yes & No & $p$-value & Yes & No & $p$-value \\
\hline \multirow{3}{*}{$\begin{array}{l}\text { Age Group } \\
\text { (Years) }\end{array}$} & 3 mon-6 Years & $65(74.71)$ & $22(25.29)$ & \multirow{3}{*}{0.029} & $31(35.63)$ & $56(74.37)$ & \multirow{3}{*}{0.400} \\
\hline & 7 Years-9 Years & $3(37.5)$ & $5(62.5)$ & & $1(12.5)$ & 7 (97.5) & \\
\hline & 10 Years-12 & $2(40)$ & $3(60)$ & & $2(40)$ & $3(60)$ & \\
\hline \multirow{2}{*}{ Gender } & Male & $42(67.74)$ & $20(32.26)$ & \multirow{2}{*}{0.529} & $20(32.26)$ & $42(67.74)$ & \multirow{2}{*}{0.639} \\
\hline & Female & $28(73.68)$ & $10(26.62)$ & & $14(36.84)$ & $24(63.16)$ & \\
\hline \multirow{3}{*}{ Cleft Type } & Lip and palate & $46(71.87)$ & $18(28.13)$ & \multirow{3}{*}{$<0.001$} & $25(39.06)$ & $39(60.94)$ & \multirow{3}{*}{0.068} \\
\hline & Lip & $1(11.11$ & $8(88.89)$ & & - & $9(100)$ & \\
\hline & Palate & $23(85.18)$ & $4(14.82)$ & & $9(33.33)$ & $18(66.67)$ & \\
\hline \multirow{2}{*}{ Operated } & Yes & $24(48.98)$ & $25(51.02)$ & \multirow{2}{*}{$<0.001$} & $15(30.61)$ & $34(69.39)$ & \multirow{2}{*}{0.483} \\
\hline & No & $46(90.20)$ & $5(9.80)$ & & $19(37.25)$ & $32(62.75)$ & \\
\hline
\end{tabular}

Table-II: Association of middle ear disorder with hearing loss (pearson chi-square test) (n=100).

\begin{tabular}{|c|c|c|c|c|}
\hline \multirow{2}{*}{\multicolumn{2}{|c|}{ Variable }} & \multicolumn{2}{|c|}{ Hearing Loss } & \multirow{2}{*}{$p$-value } \\
\hline & & \multirow{2}{*}{$\begin{array}{c}\text { Present } \\
34(48.58 \%)\end{array}$} & \multirow{2}{*}{$\begin{array}{c}\text { Absent } \\
36(51.42 \%)\end{array}$} & \\
\hline Middle Ear & Present & & & \\
\hline Disorders & Absent & - & $30(100 \%)$ & \\
\hline \multirow{7}{*}{$\begin{array}{l}\text { Type of Middle } \\
\text { Ear Disorder }\end{array}$} & Acute otitis media & $8(100)$ & - & \multirow{7}{*}{$<0.001$} \\
\hline & Acute suppurative otitis media & $5(100)$ & - & \\
\hline & Chronic suppurative otitis media & $4(100)$ & - & \\
\hline & Eustachian tube dysfunction & $1(20)$ & $5(80)$ & \\
\hline & Otitis media with effusion & $12(27.91)$ & $31(72.09)$ & \\
\hline & Tympanic membrane perforation. & $2(100)$ & - & \\
\hline & Tympanosclerosis & $2(100)$ & - & \\
\hline
\end{tabular}

\section{DISCUSSION}

Current study revealed a high frequency of MEDs of $70 \%$ among cleft lip and or palate cases. Similarly, in a clinical study by Klaiarasi et al, revealed that $58.3 \%$ had MEDs. ${ }^{8}$ Flynn and Lohmander also concluded in chronic suppurative otitis media in $18.5 \%$ and acute suppurative otitis media in $17.6 \% .{ }^{17}$

In the current study, of the $70 \%$ cases with MED's, $34(48.57 \%)$ were having HL, while $36(51.43 \%)$ were having normal hearing; compared to no HL reported 
in cases in which MEDs were not present. This observation was statistically significant with $p<0.001$. Thanawirattananit et al also reported high prevalence of HL in cleft lip and palate children at 5 years of age. ${ }^{18}$

A statistically significant association of MEDs with age, cleft type and surgery was noted. Compared to other age groups majority of cleft cases of age group of 3 month to 6 years developed MEDs and association was significant with $p=0.029$. Similarly, Flynn et al also reported a significant age association of MEDs in cleft cases with prevalence of $89 \%$ at 1 year of age to $10 \%$ in young adults. ${ }^{14}$ A local study reported no association across age $(p=0.988){ }^{6}$

Flynn et al reported gender association of MEDs. ${ }^{7}$ However, current study did not reveal any gender association. This was also the case with another local study with no gender association $(p=0.955){ }^{6}$

In current study MED's were also associated with cleft type with 23 out of 27 cases of cleft palate and 46 out of 64 cases of cleft lip and palate and only one case of cleft lip alone out of 9 cases reported affected and the finding was statistically significant with $p<0.001$. Interestingly though only one case of cleft lip was affected in our study, in a study by Ruegg et al, 31\% of cleft lip cases had ear infection compared to $11 \%$ controls. ${ }^{19}$ Flynn et al, also reported significantly lower prevalence of MEDs in CP. ${ }^{7}$

In present study MEDs were more common in non- operated cases (46 out of 51) compared to operated cases (24 out of 49) who underwent surgical repair of cleft lip and palate and association was significant with $p<0.001$. Also Lou et al, reported that those patients who underwent surgery for cleft repair before 3 had significantly lower prevalence of MEDs then those who underwent surgery later on 20. Hence, cleft surgery at a younger age is more beneficial in preventing MEDs. This clearly indicates the importance of surgery especially early repair in preventing and correcting middle ear disorders.

Hearing loss did not show any significant association with age, gender, cleft type and surgery $(p=0.4$, $0.63,0.06,0.48)$ in the present study. In contrast, in a study by Skuladottir et al, reported that HL was associated with cleft palate and improved significantly from childhood to adulthood. ${ }^{21}$ Also Antonelli et al, reported that age and type of surgery, for clefts, did not show statistically significant association with sequelae or hearing improvement. ${ }^{22}$ In study by Flynn et al, reported improvement of pure-tone thresholds with age but the high frequency pure tone averages did not. ${ }^{7}$ They also reported poor hearing in bilateral cleft group in comparison to others. ${ }^{7}$ In current study no significant association of HL was noted with surgery, however Jane et al, reported that HL was associated with cleft lip and improves with cleft surgery. ${ }^{23}$ Skuladottir et al, reported improved pure tone thresholds with age following repair. ${ }^{24}$

In current study MEDs were more common in non-operated cases (46 out of 51) compared to operated cases (24 out of 49) and association was significant with $p<0.001$. In contrast in a study by Rout et al, reported that surgery to repair cleft palate does not reduce MED's. ${ }^{25}$

Since MEDs including OME are found to be more in prevalence in CL/P children ( 3 months- 12 years) in the present study and literature shows that they improved with increasing age, and this is the critical age group (specifically 3 months- 5 years) for developing speech and language, so there is a need to pay special attention towards proper diagnosis, treatment, prevention of ME disorders in CL/P children.

\section{CONCLUSION}

It is concluded that middle ear disorders especially otitis media with effusion are common in cleft lip/plate children. Therefore, there was a need to do proper follow ups in cleft children to minimize the rate of middle ear disorders.

\section{Conflict of Interest: None.}

\section{Authors' Contribution}

MSI: Data Collection Analysis \& Intepretation, NM: Conception of Work \& Critical Revision, GS: Manuscript Writing and Iterature Review.

\section{REFERENCES}

1. Burg ML, Chai Y, Yao CA, Magee W III, Figueiredo JC. Epidemiology, Etiology, and Treatment of Isolated Cleft Palate. Front Physiol 2016; 7(2): 67-70.

2. Pang J, Broyles J, Redett R. Cleft Lip and Palate. Eplasty 2013; 13(2): ic25.

3. Jajja MRN, Cawasji ZF, Imran S, Khan MS, Hashmi SS, Khan TS. Oral Clefts: A review of the cases and our experience at a single institution. J Pak Med Assoc 2013; 63(9): 1098-1102.

4. Sharma RK, Nanda V. Problems of middle ear and hearing in cleft children. Indian J Plast Surg 2009; 42(Suppl): S144-148.

5. Heidsieck DS, Smarius BJ, Oomen KP, Breugem CC. The role of the tensor veli palatini muscle in the development of cleft palateassociated middle ear problems. Clin Oral Invest 2016; 20(7): 1389-1401.

6. Ahmed J, Saqulain G. Frequency of otitis media with effusion in children presenting with cleft palate. T Rehabili J 2017; 1(2); 2830.

7. Flynn T, Lohmander A, Moller C, Magnusson L. A longitudinal study of hearing and middle ear status in adolescents with cleft lip and palate. Laryng 2013; 123(6): 1374-1380.

8. Kalaiarasi R, Syed KA, Vijayakumar C, Varghese AM, John M. Clinical Study on Middle Ear Diseases in Children with Orofacial Clefts. Cureus 2018; 10(2): e2175. 


\section{Middle Ear Disorders}

9. Kuo CL, Tsao $\mathrm{YH}$, Cheng $\mathrm{HM}$, Lien $\mathrm{CF}$, Hsu $\mathrm{CH}$, Huang $\mathrm{CY}$, et al. Grommets for otitis media with effusion in children with cleft palate: a systematic review. Pediat 2014; 134(5): 983994.

10. Tanaka SA1, Mahabir RC, Jupiter DC, Menezes JM. Updating the epidemiology of cleft lip with or without cleft palate. Plast Reconstr Surg 2012; 129(3): 511-518.

11. Sundvall P, Papachristodoulou CE, Nordeman L. Diagnostic methods for acute otitis media in 1 to 12-year old children: a cross sectional study in primary health care. BMC Fam Pract 2019; 20(1): 127-130.

12. Lous J, Ryborg CT, Damsgaard JJ, Munck AP. Tympanometry in general practice: use, problems and solutions. Fam Pract 2012; 29(6): 726-732.

13. Ref C. InformedHealth.org. Hearing loss and deafness: Normal hearing and impaired hearing. [Internet]. Cologne, Germany: Institute for Quality and Efficiency in Health Care (IQWiG). 2017 1-6p. Available at: https://www.ncbi.nlm.nih.gov/books/ NBK390300/[Accessed on March 23, 2019].

14. Flynn T, Lohmander A. A longitudinal study of hearing and middle ear status in individuals with UCLP. Otol Neurotol 2014; 35(6): 989-996.

15. Narayanan DS, Pandian SS, Murugesan S, Kumar R. The incidence of secretory otitis media in cases of cleft palate. Journal of clinical and diagnostic research: J Clin Diagn Res 2013; 7(7): 1383-1386.

16. Lithovius RH, Lehtonen V, Autio TJ, Harila V, Anttonen V, Sándor GK, et al. The association of cleft severity and cleft palate repair technique on hearing outcomes in children in northern Finland. J Craniomaxillofac Surg 2015; 43(9): 1863-1867.
17. Kumari MS, Madhavi J, Krishna NB, Meghanadh KR, Jyothy A. Prevalence and associated risk factors of otitis media and its subtypes in South Indian population. Egypt J Ear Nose Throat Allied Sci 2016; 17(2): 57-62

18. Thanawirattananit $P$, Prathanee B. Five-Year Hearing Outcomes in Children with Cleft Lip/Palate. J Med Assoc Thai 2016; 99 (Suppl-5): S92-S96.

19. Ruegg TA, Cooper ME, Leslie EJ, Ford MD, Wehby GL, Deleyiannis FW, et al. Ear Infection in Isolated Cleft Lip: Etiological Implications. Cleft Palate Craniofac J 2017; 54(2): 189-192.

20. Lou Q, Zhu H, Luo Y, Zhou Z, Ma L, Ma X, et al. The Effects of Age at Cleft Palate Repair on Middle Ear Function and Hearing Level. Cleft Palate Craniofac J 2018; 55(5): 753-757.

21. Skuladottir H, Sivertsen A, Assmus J, Remme AR, Dahlen M, Vindenes H. Hearing outcomes in patients with cleft lip/palate. Cleft Palate Craniofac J 2015; 52(2): 23-31.

22. Antonelli PJ, Jorge JC, Feniman MR, Piazentin-Penna SH, DutkaSouza JC, Seagle MB, et al. Otologic and audiologic outcomes with the Furlow and von Langenbeck with intravelar veloplasty palatoplasties in unilateral cleft lip and palate. Cleft Palate Craniofac J 2011; 48(4): 412-418.

23. Jain A, Yadav A, Bhola N. Effect of palato-plasty on hearing ability of nonsyndromic cleft palate patients: a prospective clinical study. J Cleft Lip Palate Craniofac Anomal 2017; 4(2): 114-119.

24. Skuladottir H, Sivertsen A, Assmus J, Remme AR, Dahlen M, Vindenes H. Hearing outcomes in patients with cleft lip/palate. Cleft Palate Craniofac J 2015; 52(2): 23-31.

25. Rout SK, Baliarsing S, Lath MK, Debnath A, Dash SP. Does cleft palate repair reduce the incidence of middle ear pathology? J Cleft Lip Palate Craniofac Anomal 2016; 3(2): 95-99. 